\title{
Finned Fuel Element Two-Phase Flow Parameter Measurements Using Real-Time Neutron Radiography*
}

\author{
In-Cheol LIM**, Glenn HARVEL*** and Jen-Shih CHANG**** \\ ${ }^{* *}$ On leave from KAERI \\ P.O. Box 105 Yuseong, Daejon, Korea \\ E-mail:iclim@kaeri.re.kr \\ *** School of Energy Systems and Nuclear Science \\ University of Ontario Institute of Technology, Oshawa, Canada \\ E-mail:Glenn.Harvel@uoit.ca \\ **** MclARS and Department of Engineering Physics \\ McMaster University, Hamilton, Canada \\ E-mail:changj@mcmaster.ca
}

\begin{abstract}
The measurement of two-phase flow parameters for development of constitutive relationships for the HANARO/MAPLE type finned fuel using Real-Time Neutron Radiography (RTNR) is discussed in this paper. A single element finned Fuel Element Simulator (FES) was used with Freon 134a as the working fluid. To observe the effect of a spacer device on void distribution, single pin tests were performed with and without a spacer present. By analyzing the RTNR images using image processing, the effects of the spacer on the time-averaged and instantaneous void fraction distribution were studied. For the experimental results without a spacer, the time-averaged local void distribution is radially asymmetric and the degree of void fluctuation increases with a decreasing frequency along the heated channel, where the observed asymmetry may be caused by flow induced vibration. For the experimental results with a spacer, the spacer clearly limits any significant vibration and the local void distribution becomes more symmetrical. The spacer however does generate an axial void fraction maximum at the upstream of the spacer with a small depletion zone at the exit of the spacer. By analysis of the instantaneous local void distribution, void fluctuation at the heated wall due to boiling was clearly observed. Also, the agglomeration and breakup of the cold-wall void was evident. The dynamic effects of the local void transients will be discussed in detail.
\end{abstract}

Key words: Two-Phase Flow, Void Fraction, Neutron Radiography, Finned Fuel Element, Flow Boiling, Spacer Effect

\section{Introduction}

One advanced technique for real time multi-dimensional void fraction measurement and flow visualization is real-time radiography using either $\mathrm{X}$ rays or neutrons. X-ray imaging has been successfully performed for multiphase flows under some conditions but have difficulty penetrating most metals due to the high attenuating power of high atomic number materials due to the large number of electrons present ${ }^{(1,2,3,4)}$. Real-Time Neutron Radiography (RTNR) is a complementary technique to X-ray radiography that allows for 
the measurement of time dependent local void fraction as a function of the spatial $r, z$, and temporal $t$ coordinates. Robinson studied neutron radiography using the neutron beam from the pulse operation TRIGA research reactor ${ }^{(5)}$. Robinson and Wang applied their neutron radiography techniques to pool boiling phenomena and the movement of steam and vapour $^{(5)}$. Lindsay et al. observed the stream of oil in a transmission unit for an automobile $^{(6)}$. Hibiki et al. used neutron radiography to study two-phase flow in narrow rectangular ducts ${ }^{(7)}$. Sonoda et al. applied a tomographic method to measure the 3 -dimensional void fraction using neutron radiography ${ }^{(8)}$. Cimbala et al. used neutron radiography to visualize streaklines in flow around objects and thus was able to visualize flow disturbances near the surface ${ }^{(9)}$. Typically, RTNR has less attenuation than X-rays for metal pipe systems and thus is able to visualize the flow inside experimental apparatus that simulate real geometries and test conditions ${ }^{(10,11,12,13)}$.

A key limitation for nuclear fuel is critical heat flux (CHF). Researchers have studied the mechanism of CHF in an attempt to model the physical phenomena ${ }^{(14,15)}$. The main difficulty in developing an accurate model has been obtaining the information regarding the phenomena close to the heated wall. Galloway et al. used a photomicrography based technique to obtain this information ${ }^{(16)}$. Other researchers have studied the effect of heater length and orientation ${ }^{(17)}$. The general consensus is that CHF is significantly geometry dependent. As such, CHF can be influenced by geometry effects such as the addition of fins or spacer elements.

Many heating element designs have in common longitudinal finned elements to enhance the heat transfer in the fuel assemblies. The element spacers are used to maintain the gap between the fuel elements ${ }^{(18)}$. At this moment, no comprehensive study has investigated the effect of a finned element spacer on the time averaged and instantaneous void distribution in a finned element channel.

Harvel et $\mathrm{al}^{(19)}$ has measured the cross-sectional averaged void fraction in a single-element flow channel using gamma densitometer and capacitance transducer devices. However, no spacer was used in the tests and the local void distribution was not observed. Harvel et $\mathrm{al}^{(20)}$ also conducted capacitance void transducer time dependant void measurements in air-water flow with MAPLE type fuel elements and significant bundle effects on the transient behavior of void were observed.

In this research, the time-averaged and instantaneous void distributions were obtained by processing of the RTNR images from the Freon (134a) boiling experiments for the single finned element channel.

\section{Experimental Apparatus and imaging Method}

\subsection{RTNR Facility}

The RTNR facility used in this work was developed in earlier studies and the instrumentation is discussed in detail in the references ${ }^{(11,21,22)}$, hence only a summary of the instrumentation is provided here for completeness.

An LTV Co., model NRTV-2 Real-Time Neutron Radiography camera is used as the central component of the RTNR system ${ }^{(11)}$. The other components in the system include a time code generator (Telcom Research Model T5010), a Mitsubishi video cassette recorder (VHS and S-VHS), an image processing board (Data Translation DT2853, DT2861;DT3152), and a personal computer (Pentium II, HLI++ image software).

The RTNR camera generates a standard RS-330 video signal to a VCR for video storage at a sample rate of 30 frames/second. The video can then be acquired by the image processing board for enhancement and analysis by computer. 


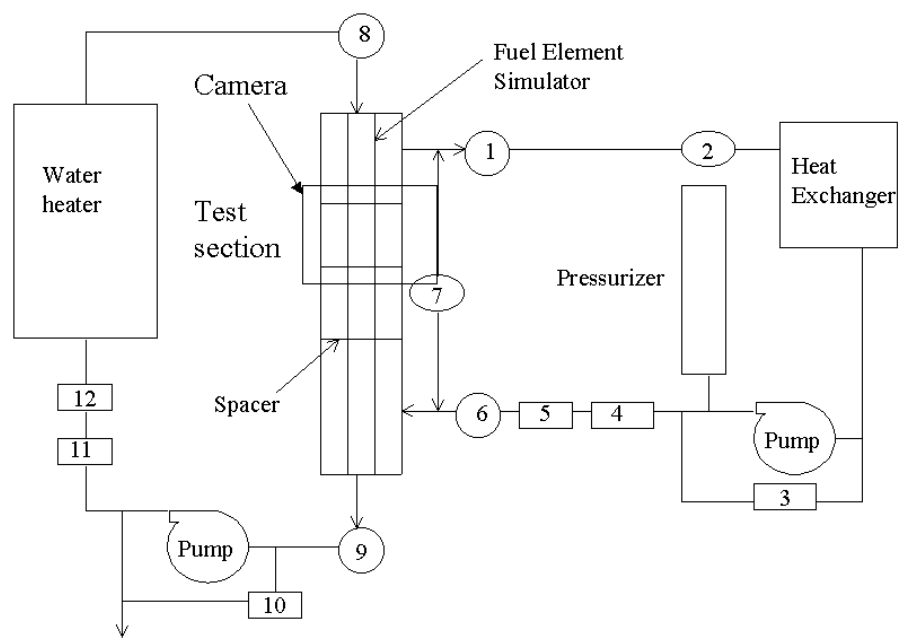

1. R134a outlet temperature

4. Flow control valve

7. Pressure drop measurement

10. Bypass valve
2. R134a outlet pressure

5. Venturi flow meter

11. Flow control valve
3. Bypass valve

6. R134a inlet temperature

9. Water outlet temperature 12. Turbine flow meter

Fig 1: Single pin test loop

The RTNR camera operates under relatively low thermal neutron fluxes ${ }^{(11)}$; on the order from $10^{4}-10^{6} \mathrm{n} /\left(\mathrm{cm}^{2}-\mathrm{s}\right)$. The spatial resolution of the RTNR camera is approximately 1 $\mathrm{mm}$ for a high contrast image for a region of $20.0 \mathrm{~cm} \mathrm{X} 20.0 \mathrm{~cm}$. The temporal resolution of the system is limited by the sampling rate of 30 frames/s or $33.0 \mathrm{~ms}$ ( $16.5 \mathrm{~ms}$ per field). The exposure time for each image is also $33.0 \mathrm{~ms}$ as the camera uses a continuous exposure feature.

The Real-Time Neutron Radiography system is used in the neutron radiography facility at the McMaster Nuclear Reactor(MNR). The neutron flux for the MNR neutron radiography facility is approximately $10^{6} \mathrm{n} /\left(\mathrm{cm}^{2}-s\right)$ when the reactor is operated at 2.0 $\mathrm{MW}_{\text {th }}$ power.

\subsection{Single Element Experimental Apparatus and Instruments}

To observe the effect of spacers on the void distribution, two sets of tests were performed; first set was performed by using a test section having three spacers and the second was done by using a test section without spacers. The test loop for the finned fuel element simulator is shown in Fig. 1. The element is heated by the hot water flowing through the inside of the finned element. The finned element was inserted into a 15.75 $\mathrm{mm}$ ID Aluminium tube. The temperatures of the Freon side and the water side were measured by type-T thermocouples. The water flow rate was measured by a turbine flow meter and the Freon flow was measured by a venturi meter. The system pressure was measured by a pressure transducer. 


\subsection{Image Analyses and Void Determination}

The procedure for the image analyses and determination of the void fraction are as follows ${ }^{(23)}$ :

a) A look-up table (LUT) for image capture using HLI++ was determined in such a way to maximize the dynamic range of the output grey level. The wider the dynamic range is, the less the void calculation error is. The LUT for this study is such that the input grey level between 0 to 130 is expanded to the allowable grey level between 0 and 255 .

b) The Sobel technique was applied to obtain the object edge and to obtain the degree rotation of the image which will make the image of the test section exactly vertical.

c) To remove the target integration effect ${ }^{(12)}$, a shading correction function is applied.

d) The calibration constant is found to determine the dependency of the corrected grey level on the liquid path length.

e) By using the calibration curve, and the full image and the two-phase image, the lateral void fraction distribution is obtained.

f) From the lateral void fraction distribution, the cross-sectional averaged void fraction and the local void distribution are obtained.

The pixel intensity for any image can be represented by the following equation:

$$
I(x, y, z)=I_{o} B e^{\left(-\beta_{f} \sum_{f} x_{f}\right)} e^{\left(-\beta_{w} \sum_{w} x_{w}\right)}
$$

,where $I_{f}$ represents the grey level of a pixel for the full image, $I_{o}$ is the unperturbed Grey level, $\mathrm{B}$ is the buildup factor, $\beta_{\mathrm{f}}$ and $\beta_{\mathrm{w}}$ are the calibration coefficient and $\sum_{\mathrm{f}}$ and $\sum_{\mathrm{w}}$ are the macroscopic cross-section for Freon and water respectively. $X_{f}$ and $X_{w}$ are the liquid Freon path length and the water path length. $\mathrm{X}_{\mathrm{fmax}}$ and $\mathrm{X}_{\mathrm{wmax}}$ are the path lengths for a full test section, i..e no void fraction.

As the water path length is fixed, $X_{w}$ is equal to $X_{w \max }$ in any pixel. Thus, Eq. 1 can be used to determine the line-averaged void fraction which can be expressed by the following equation:

$$
\overline{\alpha(y, z)}=1-\frac{x_{f}}{x_{f \max }}=\frac{1}{\beta \sum_{f} x_{f \max }} \ln \left(\frac{I}{I_{f}}\right)
$$

The lateral void fraction does not truly represent the type of void migration under consideration as length averaging is inherent. However, weighting the void fraction with the Freon path length provides a cross-sectional averaged void fraction at each axial location $^{(24)}$. The result of the cross-sectional averaged void fraction is given by the following Equation:

$$
\overline{\alpha(z)}=\frac{\int_{0}^{y} \alpha(y, z) L(y) d y}{\int_{0}^{y} L(y) d y}
$$

,where $\mathrm{L}(\mathrm{y})$ is the beam path length.

The above expressions can be evaluated for each image and pixel. As such, each calculated value represents an instantaneous measurement corresponding to $33 \mathrm{~ms}$ or 30 
frames per second. By accounting for the beam path length and integrating across a given cross section using equation 3 , we can obtain an instantaneous cross-sectional averaged void fraction.

Time averaging results can be achieved by averaging the results of successive images. While time averaging loses the instantaneous result, it provides additional insight into the phenomena under study because there is a reduction in error caused by neutron noise which tends to average out of the results.

The local instantaneous void distribution was determined by using Mudde's technique ${ }^{(25)}$. In Mudde's technique, the void is assumed to be symmetrical and each pixel represents successive layers around the centre. This technique works reasonably well for concentric geometries such as pipes and annuli. The void fraction is calculated for the outer layers first as information on the void in just the outer layer can be obtained from pixels near the outer wall. As the calculation proceeds to the inner radii, the values are corrected with the values previously calculated. Essentially, the measured void fraction for the next ring in represents a path length averaging of that ring plus the outer ring. Since the void fraction has already been determined for the outer ring, it is possible to calculate the void fraction for each subsequent ring.

\section{Experimental Results}

\subsection{Test Matrices and Process Data Analysis}

Experiments are performed using Freon 134a as the working fluid. The mass flux is varied from 37 to $110 \mathrm{~kg} / \mathrm{m}^{2} \mathrm{~s}$. The inlet subcooling is maintained at approximately $10^{\circ} \mathrm{C}$ and the heat flux is maintained at approximately $120 \mathrm{~kW} / \mathrm{m}^{2}$. The system pressure is maintained at approximately $640 \mathrm{kPa}(\mathrm{a})$.

\subsection{RTNR Image}

In Fig. 2, RTNR processed images for the case with and without a spacer at $50 \mathrm{~kg} / \mathrm{m}^{2} \mathrm{~s}$ of Freon mass flux is shown. The processed image was made by the subtraction of the full image from the two-phase image as discussed above. In the processed images for these figures, the darker region represents the higher void region. In Fig. 2, the spacer is easily observed. It is also observed that the void fraction has a maximum near the upstream of the spacer.

\subsection{Time and Cross-sectional Averaged Void Fraction Distribution}

The time and cross-sectional averaged axial void fraction distributions for Freon mass fluxes ranging from 50 to $110 \mathrm{~kg} / \mathrm{m}^{2} \mathrm{~s}$ were studied. A typical result with and without spacer for the higher mass flux is shown in Fig. 3.

For low mass fluxes without the presence of a spacer, the time averaged axial void fraction increases slightly with increasing elevation. With the spacer present, the averaged axial void fraction is no longer axially uniform with significant void fraction peaks before and after the spacer.

Typically, for Freon mass fluxes below $90 \mathrm{~kg} / \mathrm{m}^{2}$ s, the void fraction peak occurs just before the spacer. Above $90 \mathrm{~kg} / \mathrm{m}^{2} \mathrm{~s}$, the void fraction peak occurs on either side of the spacer. It is surmised that the larger momentum component of the flow is now strong enough to push the void past the spacer.

Fig. 4 shows the observed axial gradients in the time and cross-sectional averaged void fraction for cases both with and without a spacer and for mass fluxes of $50 \mathrm{~kg} / \mathrm{m}^{2} \mathrm{~s}$ and 110 $\mathrm{kg} / \mathrm{m}^{2} \mathrm{~s}$. Note that regardless of mass flux, the void gradients are the same when no spacer is present. However, when a spacer is present, the void gradient is no longer constant. 


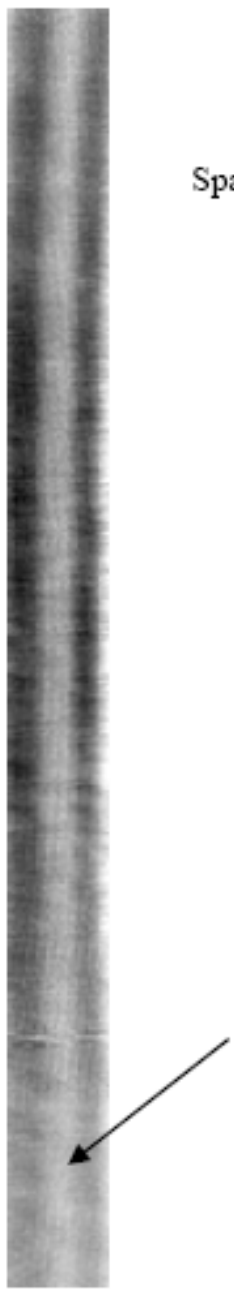

(a)

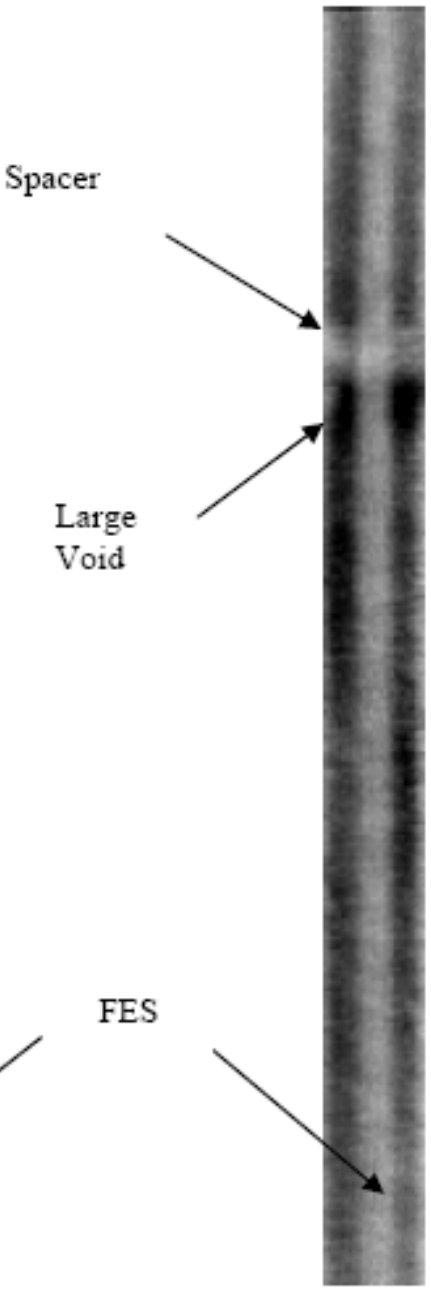

(b)

Fig. 2: $50 \mathrm{~kg} / \mathrm{m}^{2} \mathrm{~s}$ (a) without spacer, (b) with spacer. Dark colour corresponds to high void. Bright colour corresponds to low void.

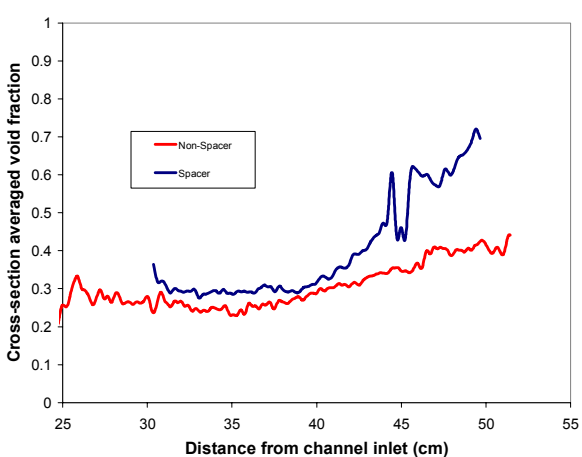

Fig. 3: Time averaged axial void fraction for $110 \mathrm{~kg} / \mathrm{m}^{2} \mathrm{~s}$ both with and without a spacer.

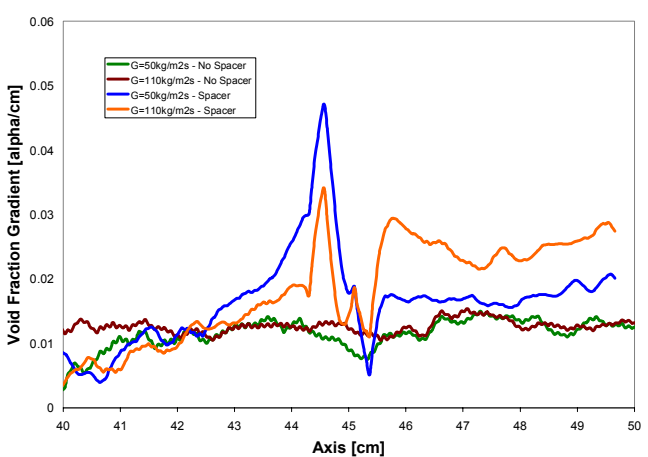

Fig. 4: A comparison of the void gradient at 50 and $110 \mathrm{~kg} / \mathrm{m}^{2} \mathrm{~s}$ for both with and without a spacer 
Hence, the presence of the spacer significantly affects the acceleration component of the two-phase flow. The disturbance after the spacer is expected to decrease as the flow re-develops after the presence of the spacer.

Another observation is that the presence of the first and second spacers at $0 \mathrm{~cm}$ and 29 $\mathrm{cm}$ in the channel did not introduce such disturbances in the flow. The probable cause of the lack of influence by the first and second spacers is likely due to a lower void fraction and a more homogeneous flow distribution. By the time the third spacer is approached, a significant amount of void has been generated and the flow is likely non-homogeneous.

Figure 5(a) show the local void fraction for the case without a spacer and a Freon mass flux of $110 \mathrm{~kg} / \mathrm{m}^{2} \mathrm{~s}$. The majority of the local void fraction is distributed with a range of 0.2 to 0.4 . The void is evenly distributed with a slight tendency towards the left side of the channel. This is likely due to the fact that the channel and the fuel element simulator cannot be perfectly vertical and hence the buoyancy force is slightly off the axial direction.

Figure 5(b) shows the time averaged local void fraction distributions for the case with a spacer and a Freon mass Flux of $110 \mathrm{~kg} / \mathrm{m}^{2} \mathrm{~s}$. Note that also due to slight variances in process boundary conditions (heat flux, pressure, inlet subcooling) that this case has a slightly higher heat content than does the similar case shown in Fig. 5(a) without a spacer. Hence, not only is a spacer present but slightly more void is present as well.

Figure 5(b) shows that the local void fraction distribution below the spacer is quite uniform in the range of 0.12 to 0.4 and is thus very similar to the same situation without a spacer. However, above the spacer, the local void fraction has increased significantly due to two factors. One is the extra heat addition. The second is that the spacer has introduced a region where void fraction can be trapped.

Note that the results observed in Fig. 5(a) are typical for the case without spacers for all tests at different Freon mass fluxes. Essentially, as the mass flux decreases, the average void fraction increases as expected but the flow remains uniform and homogeneous. This observation is expected to break down once the mass flux is small enough such that the void fraction is large enough to form slug flow or churn flow. At the lowest flow rate tested, there is some indication that the flow regime has indeed changed and the local void distribution is becoming non-homogeneous even when time averaged.

In the case where a spacer is present, the homogeneous behaviour is also observed similar to that for the cases without a spacer. In addition, the local void begins to collect before the spacer. More and more void becomes trapped before the spacer as the Freon mass flux decreases. Since the channel is vertical, the spacer is effectively acting as a flow blockage and the higher momentum liquid is passing through the spacer and the lower momentum void is being trapped. As mass flux, and hence momentum increases, the Freon liquid acts similar to a ram and pushes the fluid through the spacer.

Figure 5(c) supports this hypothesis by showing a void peak before the spacer at a slightly lower mass flux $\left(95 \mathrm{~kg} / \mathrm{m}^{2} \mathrm{~s}\right)$ than for Fig. 5(b).

The point where the flow becomes able to push the vapour through the spacer is not entirely clear and more experiments are required. Also, it is expected that this behaviour will change significantly based upon the type of upstream flow regime. Non-homogeneous flow regimes are expected to provide greater turbulence and thus have different behaviour.

\subsection{Instantaneous Void Fraction}

Instantaneous void fraction distributions were analyzed for all cases. First, visual observations indicated that for the lower Freon mass fluxes, slug flow was indeed present as Gouse and Hwang ${ }^{(26)}$ suggested. Analysis of the instantaneous void distributions support 
the visual observations. Also, the quantitative analysis further shows that at higher axial locations, the amount of fluctuation increases and the fluctuation frequency decreases. This indicates that the vapor bubble size is increasing due to additional vapour generation and agglomeration.

Calculations of instantaneous void distributions at higher Freon mass fluxes (110 $\mathrm{kg} / \mathrm{m}^{2} \mathrm{~s}$ ) do not show slug flow, but instead indicate a more bubbly flow or homogeneous pattern supporting the observations made from the time averaged void distribution analysis.

The time-dependent fluctuation of void fraction at several locations along the channel. At $Z=37 \mathrm{~cm}$, the mid-point between the second spacer and the third spacer, the void wave shape is very similar to that for without a spacer. However, at $Z=44 \mathrm{~cm}$, just below the spacer, the fluctuation amplitude increases and is larger than the fluctuation for without a spacer. The void wave at $Z=49 \mathrm{~cm}$ is similar to that at $\mathrm{Z}=37 \mathrm{~cm}$, which means the spacer effect almost disappears at this location.

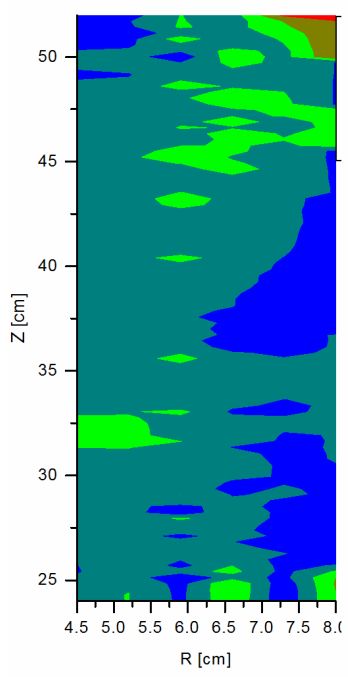

(a)

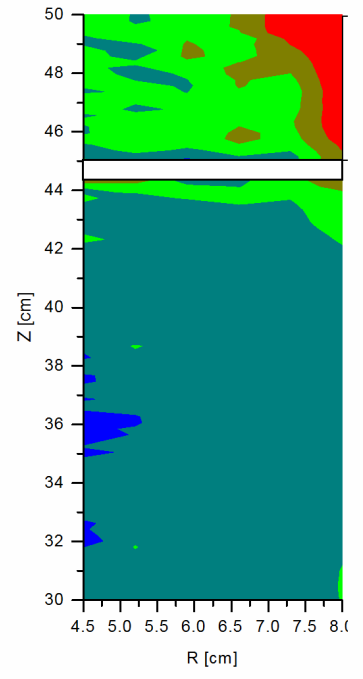

(b)

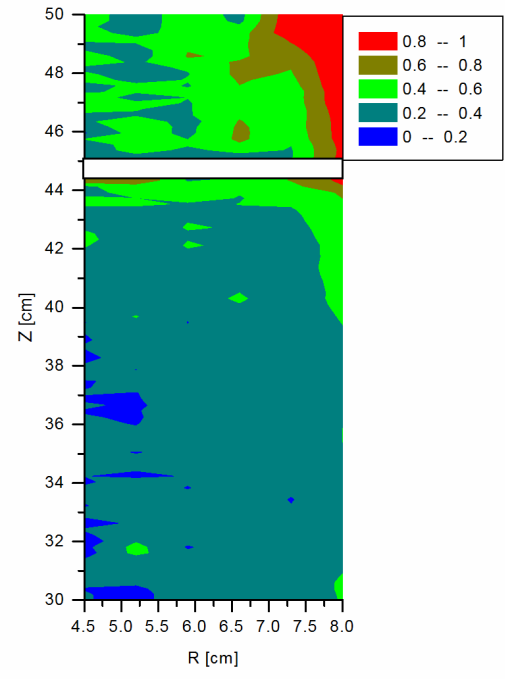

(c)

Fig. 5: Time averaged local void fraction distributions of boiling Freon in a vertical annulus where Blue is low void and Red is high void. $4.5 \mathrm{~cm}$ radius is the heated wall and $8.0 \mathrm{~cm}$ is the outer wall of the annulus: (a) mass flux of $110 \mathrm{~kg} / \mathrm{m}^{2} \mathrm{~s}$ without a spacer, (b) mass flux of $110 \mathrm{~kg} / \mathrm{m}^{2} \mathrm{~s}$ with a spacer, (c) mass flux of $95 \mathrm{~kg} / \mathrm{m}^{2} \mathrm{~s}$ with a spacer.

The instantaneous local void fraction distributions show where the fluctuation of void at the heated wall was due to boiling. Also, the propagation of the void wave, the agglomeration, and breakup of the wall void are also observed.

An instantaneous cross sectional averaged void fraction trace is shown in Fig. 6 for a mass flux of $50 \mathrm{~kg} / \mathrm{m}^{2}-\mathrm{s}$ without a spacer. The measurements are taken at $37 \mathrm{~cm}$ and 44 $\mathrm{cm}$. The traces indicate that the average void fraction is higher at $44 \mathrm{~cm}$ as expected. The two traces can be correlated to determine the velocity of the void fraction peaks.

Using the instantaneous cross-sectional averaged void fraction results, it is possible to identify the centroid of a void as it passes a certain elevation. This same void packet will eventually arrive at a higher elevation and the time that the centroid of the void passes this location can be measured. This provides information related to the vapor phase velocity. Note that variances in the vapor phase velocity are expected since the measurements may indicate a void packet and not necessarily a single bubble. Thus, it is possible that the void packet is accelerating or decelerating due to different bubble shapes and sizes. 
The velocity of the vapour phase is determined in a range of $10.1 \mathrm{~cm} / \mathrm{s}$ to $12.7 \mathrm{~cm} / \mathrm{s}$. The data suggests that each successive void packet is accelerating. The results also suggest that the void packets have a tendency to change in magnitude. Review of the images indicate that some of the changes are due to agglomeration while others are due to a break up of the packet.

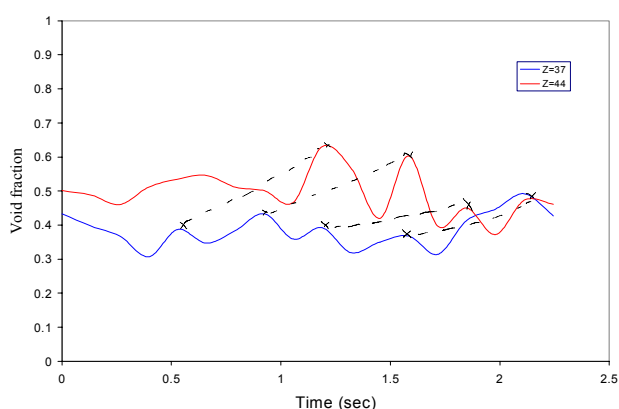

Fig. 6: Instantaneous Variation in the Cross Sectional Averaged Void Fraction without Spacer Present. Blue is $37 \mathrm{~cm}$ height location. Red is $44 \mathrm{~cm}$ height location.

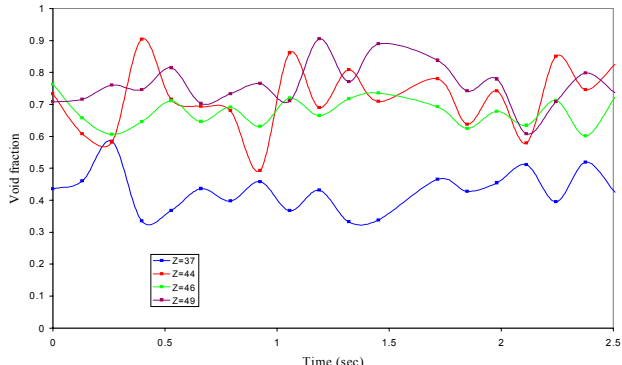

Fig. 7: Instantaneous Variation in the Cross Sectional Averaged Void Fraction for the case with a Spacer Present.

Similar instantaneous cross sectional averaged void fraction traces are shown in Fig. 7 for a mass flux of $50 \mathrm{~kg} / \mathrm{m}^{2}$-s but for the case where the spacer is included. The measurements are taken at $37 \mathrm{~cm}, 44 \mathrm{~cm}, 46 \mathrm{~cm}$, and $49 \mathrm{~cm}$ from the inlet of the test section. $44 \mathrm{~cm}$ is just before the spacer and $46 \mathrm{~cm}$ is just after the spacer. At $37 \mathrm{~cm}$, the mid-point between the second spacer and the third spacer, the void wave shape is very similar to that for without a spacer. However, at $Z=44 \mathrm{~cm}$, just below the spacer, the fluctuation amplitude increases and is larger than the fluctuation for without a spacer. The void wave at $Z=49 \mathrm{~cm}$ is similar to that at $Z=37 \mathrm{~cm}$, which means the spacer effect almost disappears at this location. The results indicate that the vapor velocity before the space is approximately $7 \mathrm{~cm} / \mathrm{s}$ before the spacer and approximately $6 \mathrm{~cm} / \mathrm{s}$ after the spacer. However, across the spacer, the vapor velocity appears to reduce to approximately $2.9 \mathrm{~cm} / \mathrm{s}$ which correlates to the spacer trapping the void in place and disturbing the flow. Review of the video images supports vapor trapping to occur at the spacer under a mass flux of 50 $\mathrm{kg} / \mathrm{m}^{2}-\mathrm{s}$.

Void trapping is further supported by the instantaneous void fraction distributions shown in Fig. 8. These images are produced by employing Mudde's technique to capture the instantaneous void fraction bout axially and radially although significant noise can exist in the images due to statistical fluctuations in the neutron beam. In this case, the void fraction can be seen moving up the flow channel and collecting both just before and after the spacer. Fig. 8 also shows that the void formation along the heated surface is evident and then transports downstream in large packets. Due to the orifice type restriction by the spacer, the shape of the void is flatter and the interface is more wavy than further upstream. This may be due to agglomeration of void from nucleation sites. The spacer effects also can be clearly shown near the outer side tube where void is clearly trapped and collapses after accumulation to certain size. Similar void trapping also can be observed on the downstream side of the spacer near the tube wall. 


\section{Energy Systems}

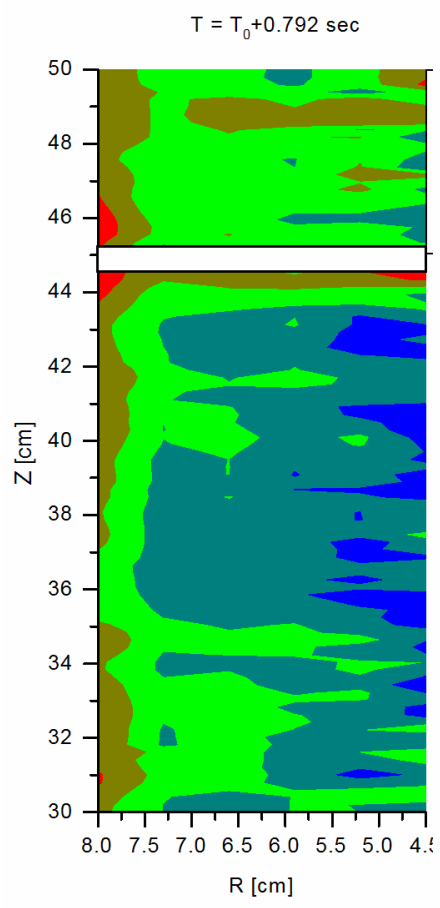

(a)

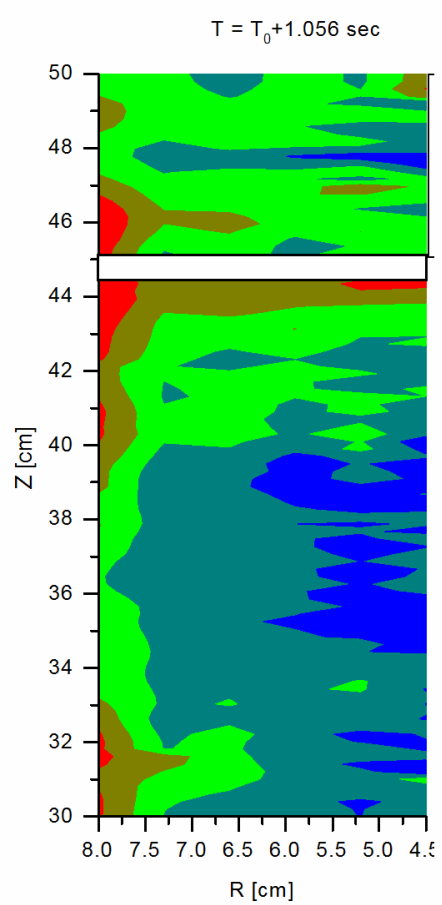

(c)

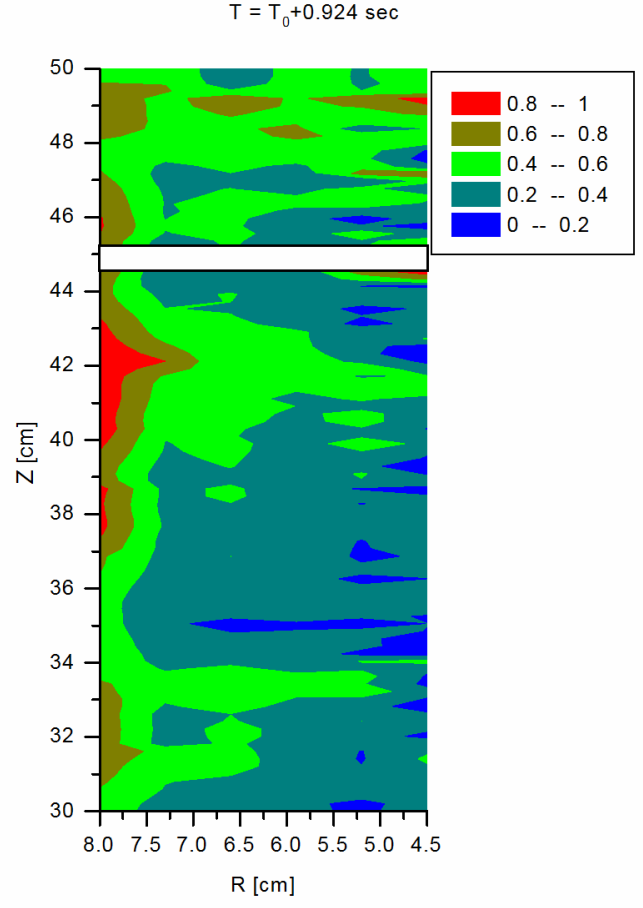

(b)

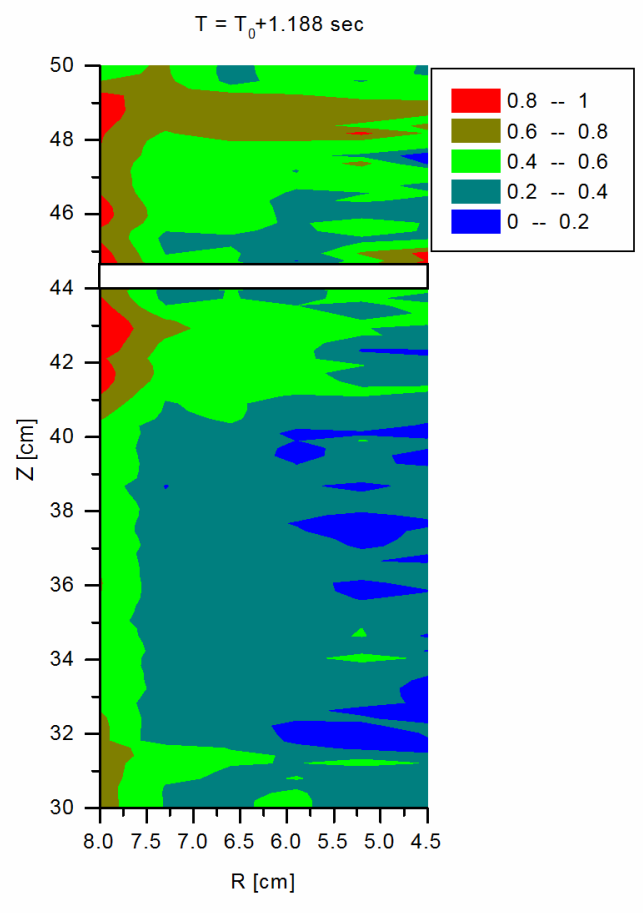

(d)

Fig. 8: Instantaneous Local Void Fraction Distribution with a spacer, $\mathrm{G}=50 \mathrm{~kg} / \mathrm{m}^{2} \mathrm{~s}$ 


\section{Conclusion}

From the image analysis of the RTNR test for the single-element flow channel subcooled flow boiling with and without spacers, the followings conclusions were drawn:

a) The cross sectional averaged void fraction axial profiles decreases with increasing Freon mass flux.

b) The spacer generates an axial void fraction maximum at the upstream of the spacer. The degree of these peaks is higher for the lower mass fluxes. At higher mass fluxes, the void fraction peaks after the spacer.

c) The spacer limits any FES vibration and local void distribution becomes more radially symmetric.

d) For the test without spacer, the time-averaged local void distribution becomes radially asymmetric. It may be due to the flow induced vibration of the FES.

e) For the case without spacer, the degree of the void fluctuation increases along the heated channel. However, the fluctuation frequency decreases along the heated channel.

f) For the case with spacer, the degree of void fluctuation is largest at the upstream of the spacer.

g) The magnitude of void fluctuation decreases as the Freon mass flux increases largely due to the homogeneity of the flow.

h) From the analysis of the instantaneous local void fraction distribution, the fluctuation of void at the heated wall due to the boiling was clearly observed. Also, the agglomeration and breakup of the cold-wall void was evident.

\section{Acknowledgements}

The authors thank N. Popov (AECL), A. Lee (AECL), V.S. Krishnan (AECL), I.W. Love (AECL-Korea), H.R. Kim (KAERI) and J.B. Lee (KAERI) for valuable discussions and comments. The authors also thank P.C. Looy, D.R. Novog and J. Cotton for technical assistance in performing the work. This work was also partly supported by KOSEF of Korea, CFI of Canada, NSERC of Canada and AECL-Korea.

\section{References}

(1) Mitsutake, T., Morooka, S., Suzuki, K., Tsunoyama, S., and Yoshimura, K., Void Fraction Estimation within Rod Bundles Based on Three-Fluid Model and Comparison with X-Ray CT Void Data, Nuclear Engineering and Design, V120,(1990), pp. 203-212.

(2) Hori, K., Kawanishi, K., Hamamura, H., Ochi, M., and Akai, M. A High Speed X-Ray Computed Tomography Scanner for Multipurpose Flow Visualization and Measurement, $4^{\text {th }}$ International Topical Meeting on Nuclear Thermalhydraulics, Operations, and Safety, April 6-8, (1994), Taipei, Taiwan.

(3) Narabayashi, T., Tobimasu, T., Nagasaka, H., and Kagawa, T., Measurement of Transient Flow Pattern by High Speed Scanning X-ray Void Fraction Meter, Measurement Techniques in Gas-Liquid Flows, (1984) pp. 259-280, Springer-Verlag,

(4) Narabayashi, T., Ishiyama T., Miyano H., and Nei, H., Measurement of Void Distribution in High Pressure Steam-Water Two-Phase Flow using High Speed X-ray Scanner, Proceedings of First International Conference on Multiphase Flows, Vol. 1, Sept. 24-27, Tsukuba, Japan, (1991) pp. 241-246.

(5) A.H. Robinson and S.L. Wang, High Speed Motion Neutron Radiography of Two-phase Flow, Neutron Radiography, J.P. Barton and P. von der Hardt(eds.),(1983) pp.653-659. 
(6) Lindsay J.T., Jones, J.D., Kauffman, C.W., and Van Pelt, B., Real-Time Neutron Radiography using a LIXI Neutron Imaging Device", Nuclear Instruments and Methods in Physics Research A, Vol. 242, (1986), pp. 525-530.

(7) Hibiki, T., Mishima, K. and Matsubayashi, M., Application of High Frame Rate Neutron Radiography with a Steady Thermal Neutron Beam to Two-Phase Flow Measurements in a Metallic Rectangular Duct, Nuclear Technology, Vol. 110, (1995), pp. 422-435.

(8) Sonoda, K., Ono, A., Takenaka, N., Fujii, T., Tazawa, S., and Nakanii, T., Visualization and Volumetric Fraction Measurement of Multiphase Flow by Neutron Radiography, Neutron Radiography(4), J.P. Barton(eds.), (1994),pp.347-354.

(9) Cimbala, J.M., Hughes, D.E., Levine, S.H., and Sathianathan D., Application of Neutron Radiography for Fluid Flow Visualization”, Nuclear Technology, Vol. 81, (1998), 435-445.

(10) Harvel, G.D., Hori, K., Kawanishi , K. and Chang, J.S. , Real-time Cross-Sectional Averaged Void Fraction Measurements in Vertical Annulus Gas-liquid Two-Phase Flow by Neutron Radiography and X-ray Tomography Technique, Nucl. Instr. And Meth. in Phys. Res. A, Vol. 371, (1996), pp.544.552.

(11) G.D. Harvel, J.S. Chang and V.S. Krishnan, Determination of Time-Dependent Void Fraction Distribution in Bubbly Two-Phase Flow By a Real-Time Neutron Radiography Technique, Nucl. Tech., V.109, (1995), pp. 132-141.

(12) G.D. Harvel, K. Hori, K. Kawanishi, J.S. Chang, Cross Sectional Void Fraction Distribution Measurement in a Vertical Annulus Two-Phase Flow by High Speed X-ray Computed Tomography and Real-Time Neutron Radiography Method, Flow Measurement \& Instr., Vol. 10, (1999), pp. 259-266.

(13) Hibiki T., Mishima, K., Yoneda, K., Fujine, S., Kanda, K., Nishihara, H., Tsuruno, A., and Matsubayashi, M., Application of Neutron Radiography to Visualization and void Fraction Measurement of Air-Water Two-Phase Flow in a Small Diameter Tube, Journal of Nuclear Science and Technology, Vol. 30, (1993), pp. 516.

(14) Hibiki, T., Mishima, K., Yoneda, K., Fujine, S., Tsuruno, A., and Matsubayashi, M. Visualization of Fluid Phenomena using a High Frame Rate Neutron radiography with a Steady Thermal Neutron Beam, Nuclear Instruments and Methods in Physics Research A, Vol. 351, (1994), pp.423-436.

(14) Lee, C.H. and Mudawar, I., A Mechanistic Critical heat Flux Model for Subcooled Flow boiling based on local bulk flow conditions, Int. J. Multiphase Flow, Vol. 14, (1988), pp. 711-728.

(15) Kumamaru, H. and Kukita, Y., Critical heat flux and heat transfer above mixture level under high pressure boil off conditions in PWR type and tight lattice type fuel bundles, Nuclear Engineering and Design, Vol. 144, (1993), pp. 257-268.

(16) Galloway, J.E., Mudawar I., CHF mechanism in flow boiling from a short heated wall -I. Examination of near wall conditions with the aid of photomicrography and high-speed video imaging, Int. J. Heat Mass Transfer, Vol. 36, (1993), pp. 2511-2526.

(17) Gersey, C.O., and Mudawar, I., Effects of heater length and orientation on the trigger mechanism for near-saturated flow boiling critical heat flux-II: Critical heat flux model, Int. J. Heat Hass Transfer, Vol.38, (1995), pp. 643-654.

(18) I.C. Lim, C.M. Sim, J.E. Cha, Y.S. Choi, N. Takenaka, Y. Saito, B.J. Jun, Measurement of the Void Fraction in a Channel Simulating the HANARO Fuel Assembly Using Neutron Radiography, Nuclear Instruments and Methods A, Vol. 542, (2005), 181-186.

(19) G.D. Harvel, J.E. Kowalski, C.K. McCallum and V.S. Krishnan, Application of Capacitance and Gamma Attenuation Techniques for Void Fraction Measurements in a Finned Annulus Channel, Heat and Mass Transfer: An Era of Change, (1992) pp. 1797-1812, Nova Sci. Pub., New York.

(20) G.D. Harvel, J.S. Chang, V.S. Krishnan, A Two-phase Flow Regime Map for a Maple-Type Nuclear Research Reactor Fuel Channel: Effect of Hexagonal Finned Bundle, 
Nuclear Tech., Vol. 118, (1997), pp.151-161.

(21) G. Harvel, J.S. Chang, V.S. Krishnan, Investigation of large amplitude stratified Waves in a CANDU-type 37 rod Nuclear Fuel Channel by a Real-Time Neutron Radiography Technique, Nuclear Engineering and Design, Vol. 200, (2000), pp. 221-231.

(22) G. Harvel, J.S. Chang, V.S. Krishnan, A Real-Time Neutron Radiography Diagnostic of a Vertical Co-Current Two-Phase Flow Channel with a Hexagonal Finned Bundle, Journal of Nuclear Society of Thailand, Vol. 4. No. 1, (2003), pp. 1-15.

(23) K. Uchimura, G.D. Harvel, T. Matsumoto, M. Kanzaki and J.S. Chang, An Image Processing Approach for Two-phase Interfaces Visualized by a Real-Time Neutron Radiography Technique, Flow Measurement \& Instr., Vol. 9, (1998), pp. 203-210.

(24) J.S. Chang and G.D. Harvel, Determination of Gas-Liquid Bubbly Column Instantaneous Interfacial Area and Void Fraction by a Real-Time Neutron Radiography Method, Chem. Eng. Sci., Vol.47, No.13/14, (1992), pp. 3639.

(25) R.F. Mudde, R.A. Bakker, and H.E.A. Van Den Akken, Noise Analysis of Transmitted Light Beams for Determining Bubble Velocity and Gas Holdup Profiles in a Bubble Column, Chem. Eng. Sci., Vol.47, No.13/14, (1992), pp. 3631.

(26) S.W. Gouse and C.C. Hwang, Visual Study of Two-Phase One-Component Flow in a Vertical Tube with heat Transfer, ASME paper 53-WA-165;MIT report 8973-1, (1965). 